\title{
An experimental model for mixed friction during running-in
}

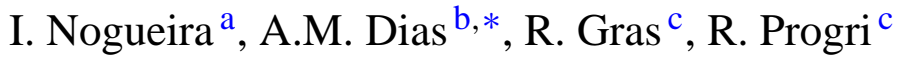 \\ ${ }^{a}$ Department Industrial Chemistry Engineering, Polytechnic Institute of Tomar, IPT-ESTT-Estrada da Serra, P-2300 Tomar, Portugal \\ ${ }^{\mathrm{b}}$ Department of Mechanical Engineering, University of Coimbra, DEM-Polo II, Pinhal de Marrocos, P-3030 Coimbra, Portugal \\ c ISMCM-CESTI, Laboratoire de Tribologie 3, Rue Fernand Hainaut, P-93407 Saint-Ouen, France
}

Received 22 March 2001; received in revised form 14 March 2002; accepted 12 April 2002

\begin{abstract}
Mechanical engineering often uses fluid lubrication to limit friction. Even in the presence of a lubricant, metallic contact between the sliding surfaces may readily occur. In running-in, the oil film thickness can be so thin that contact arises at the summit of asperities, thus, increasing both the friction coefficient and wear. Such regimes are the so-called mixed or boundary lubrication. In these situations, the friction coefficient varies continuously and it is therefore, necessary to calculate the friction coefficient at any given moment.

Given two rough parallel surfaces in a lubricated environment, a model is herein proposed whereby the friction coefficient is controlled by a single hydrodynamic parameter. This experimental analysis seeks to take into account a wide variety of factors influencing the conditions in which the contact operates: functional parameters (normal load, sliding speed, viscosity), the contact pair's mechanical properties (elastic modulus, Poisson's ratio) and surface microgeometry (as expressed by the standardised roughness parameters). This extended friction model predicts tribological behaviour in lubrication regimes: thus, by judicious choice of materials (according to the most appropriate mechanical properties and surface roughness) one can reduce the running-in period. To confirm the model, different material pairs have been tested. The tests have been conducted using a pin on disc apparatus in a 100 Neutral solvent (100 NS) oil at $20{ }^{\circ} \mathrm{C}$. Experimental results totally confirmed the model.
\end{abstract}

(C) 2002 Elsevier Science B.V. All rights reserved.

Keywords: Running-in; Hydrodynamic parameter; Friction; Lubrication regimes

\section{State of the art}

During running-in the friction and wear between two rough surfaces vary considerably over time. If the initial surface roughness of the rubbing surfaces was correctly chosen, the running-in eventually reaches a steady state. At this latter stage, the rubbing surfaces are smoother and their wear rate is low and constant. On the contrary, an inappropriate choice of roughness may lead to a rapid deterioration of the rubbing surfaces [1]. Experience shows that the surface microgeometry is one of the most important factors determining the life of mechanical components. Östvik and Christensen [2] observed that running-in consists of "squashing" down the height of the highest asperities, thereby increasing the number of asperities in contact, and raising the load-carrying capacity of the surfaces. The smoothing mechanism of surfaces during running-in should be analysed in terms of the wear of the peaks and in terms

\footnotetext{
* Corresponding author. Tel.: +351-239-790-759; fax: +351-239-790-701.

E-mail address: rene.gras@ismcm-cesti.fr (A.M. Dias).
}

of the filling in of the surface valleys by the wear debris [3]. It was observed that surface alterations lead to an apparent extension of the contact area but also to a weak tendency to reduce stress concentration. According to Pawlus [4] wear during running-in depends on both the height and the shape of the asperities' distribution. Progri et al. [5] and Robbe-Valloire et al. [6] further stated that the friction and the lubrication regimes depend on those parameters.

The lubricant plays an important part in the prevention of surface damage during running-in. Andersson et al. [7] assumed that the sliding surfaces tested in a lubricated environment become polished during running-in, they also observed that the lubrication mechanism was transformed from boundary or mixed lubrication to full film lubrication.

Robbe-Valloire et al. [8] present a statistical description of rough surfaces in a lubricated environment. They propose an analysis for interactions between asperities and lubricant. When the two surfaces are very close the highest asperities come into contact. In this model, the friction force on the surfaces is represented by two terms: one viscous and the other solid. According to hydrodynamic theory, the viscous force results from the sliding motion of the fluid and an oil 
film separates the asperities. In the solid term, the force is produced by the interaction of the asperities on the sliding surfaces.

In mixed lubrication the friction coefficient may also be described as an addition of two terms, one relating to the viscous friction $\mu_{\mathrm{v}}$ and the other to the solid friction $\mu_{\mathrm{s}}$ :

$\mu=(1-\lambda) \mu_{\mathrm{v}}+\lambda \mu_{\mathrm{s}}$

The solid contact rate $\lambda$ depends on increased contact area, on the distance between the surfaces and also on the speed. Some authors propose models to define $\lambda$, but for those models the $\lambda$ determination is often difficult to achieve. However, Progri et al. [5] propose a simple model using $\lambda$ as a quotient between the partial solid force and the total force on the surface. He has established for all $\lambda \in[0,1]$ that $\lambda$ varies with the charge, speed and the surface state.

In lubricated friction, a classical result states that the friction coefficient is a function of speed $V$, contact pressure $p$ and lubricant viscosity $\eta$. The so-called Stribeck curve perfectly describes the variation of the friction coefficient as a function of those variables combined in a unique hydrodynamic parameter, $S$.

$S=\frac{\eta V}{p}$

Three different intervals corresponding to three different lubrication regimes are presented in the Stribeck diagram (Fig. 1).

Many authors [5,8-10] demonstrate in their works that the minimum lubricant film thickness and the surface roughness of the sliding pair determine lubricant film breakdown. Despite the major theoretical advances from these studies, a need remained for experimental confirmation such as those obtained by Emmens [11] or Felder and Samper [12] on deep drawing. The aforesaid authors studied the influence of surface asperities on the hydrodynamic parameter. Emmens and Felder propose two hydrodynamic parameters, designated $S_{\mathrm{E}}$ and $S_{\mathrm{F}}$, respectively:

$S_{\mathrm{E}}=\frac{\eta V}{p} \frac{1}{R_{\mathrm{pm}}^{2}}$

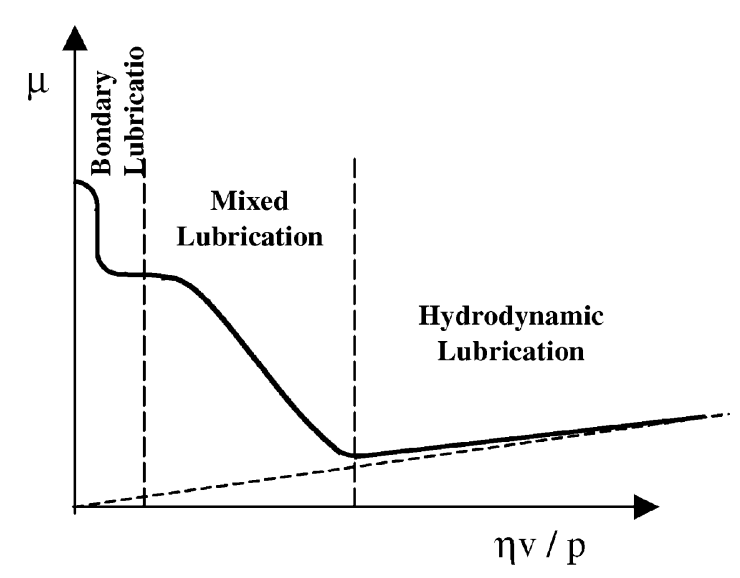

Fig. 1. The Stribeck diagram.
$S_{\mathrm{F}}=\frac{3 \eta V}{p} \frac{\ell}{R_{\mathrm{a}}^{2}}$

where $R_{\mathrm{pm}}$ is the average distance of five maximal peak heights to the mean line of the profile, and $R_{\mathrm{a}}$ the arithmetic mean of the height of the profile and $\ell$ describes the space between two consecutive asperities. On the basis of their experiments, the use of these parameters gives closer match of points to a master curve than that of the Stribeck parameter.

In a lubricated system, many authors focus on the importance of mechanical properties such as Young's modulus for the pair. They state that the higher Young's modulus the greater the pressures created on the contact bodies. As a consequence, the lubrication regime is expected to shift towards more stringent boundary conditions and results in higher friction coefficients. In the Hertz theory of elastic contact, the deformation of asperities depends on the load on the contact. Assuming the asperities to be spherical caps, the load equation is a function of the contact radius, which depends on the elastic modulus.

Emmens and Felder only tested one material with several microgeometries, this study seeks to introduce mechanical characteristics into the hydrodynamic parameter, thus, taking into account the material properties of the contact pair.

\section{Materials and procedures}

Friction measurements have been carried out using a pin on disc tribometer (RENAULT-ISMCM) presented in Fig. 2.

In the tests, the evolution of the friction coefficient was measured as a function of the sliding speed. In each test, the frictional force was continuously recorded.

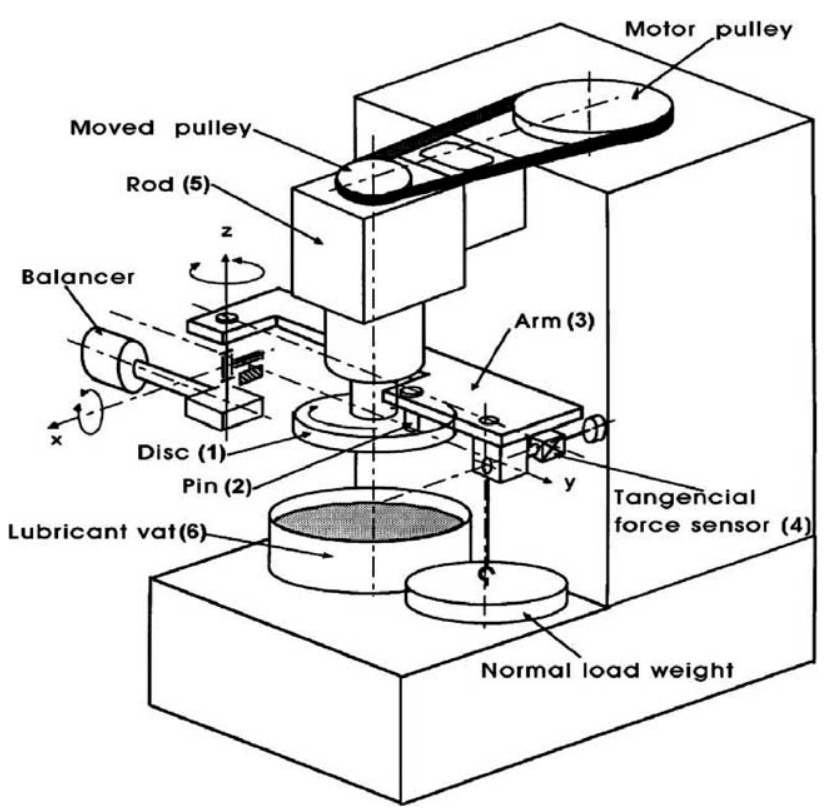

Fig. 2. The tribometer running principle scheme. 


\subsection{Tribometer}

The tribometer apparatus involves in placing two surfaces in contact: a stationary surface, the pin (2), connected to the balanced load arm (3) with double articulation. The pin slides on a moving surface; the disc (1) rotates with a uniform rotational speed driven by a motor assembly (5). A tangential force sensor (4) measures the friction force. The pair is placed in a lubricant bath (6). The contact between the surfaces is plane-plane. This tribometer enables the adjustment of the normal force on the pin by weights suspended from the edge of the arm. Oil temperature and speed are adjusted as required.

\subsection{Materials tested}

The discs were made from a hardened steel $(855 \mathrm{HV})$ AFNOR $100 \mathrm{C} 6$ having an excellent wear and compression contact resistance. The discs' surfaces when polished, present a very fine finish, $R_{\mathrm{a}}=0.04 \mu \mathrm{m}$ and $R_{\mathrm{pm}}=$ $0.12 \mu \mathrm{m}$. After the tests it was not possible to observe significant damage on the discs surface.

The present study has focused on the softer material surfaces, that is, the pins whose hardness is lower than that of the discs. Two surface finishing by sandpaper 80 and 400 were used for the pins. To warrant a perfect parallelism between the pin and the disc surfaces these finishes were made on the tribometer. The finished procedure consisted in covering some discs with sandpaper. The discs turned at low speed $(0.5 \mathrm{~Hz})$, under a normal force of $5 \mathrm{~N}$ during $15 \mathrm{~s}$.

Pins of different materials were selected to study the influence of the mechanical properties. However, the tests made showed seizure problems on the stainless steel-steel pair for the condition of $5 \mathrm{MPa}$, as a contact pressure with fine surface finish, as can be seen in Fig. 3, which shows an overview of the pin surface damage. Consequently, it was decided to continue this study with pairs excluding the stainless steel-steel pair.

The main mechanical characteristics and chemical compositions of the several materials are shown in Tables 1 and 2 .

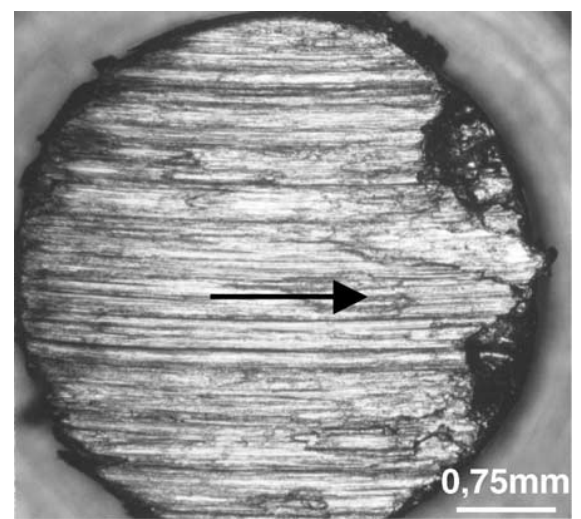

Fig. 3. Overview of the seizure surface of the stainless steel pin after variable speed test, contact pressure $5 \mathrm{MPa}$, surface finishing by sandpaper 400.

For all pins the sliding surface of pin has a diameter of $3 \times 10^{-3} \mathrm{~m}$

The lubricant 100 Neutral solvent (100 NS), a mineral paraffin-based oil without additives, was used. The work temperature was $20^{\circ} \mathrm{C}$, which corresponds to a cinematic viscosity of $40 \mathrm{~mm}^{2} \mathrm{~s}^{-1}$.

\subsection{Test procedures}

Two series of tests were conducted on the tribometer. The first series was conducted at a variable speed and was divided in two parts. For each pressure and the given oil at work temperature, the sliding speed was varied sequentially as a step function from a maximum $\left(3 \mathrm{~m} \mathrm{~s}^{-1}\right)$ to a minimum value $\left(0.1 \mathrm{~m} \mathrm{~s}^{-1}\right)$ : first part; and then again to a maximum value: second part. To simulate the conditions of a sequential running-in and transient phases each decreasing and increasing function has nine speed stages, each speed stage lasted 1 min, Fig. 4. The friction coefficient was measured at every speed stage. The analysis to the frictional diagrams reveals the influence of several variables (surface roughness, sliding speed, normal pressure and the material pairs) on the friction coefficient. The pressures used in the tests were 5,

Table 1

The main characteristics of the tested material

\begin{tabular}{|c|c|c|c|c|c|c|c|}
\hline \multirow[t]{2}{*}{ Material } & \multirow{2}{*}{$\begin{array}{l}\text { Modulus of } \\
\text { elasticity } \\
(\mathrm{GPa})\end{array}$} & \multirow{2}{*}{$\begin{array}{l}\text { Yield stress } \\
\text { minimum } \\
(\mathrm{MPa})\end{array}$} & \multirow[t]{2}{*}{$\begin{array}{l}\text { Poisson's } \\
\text { ratio }\end{array}$} & \multirow{2}{*}{$\begin{array}{l}\text { Elongation }(\%) \\
50 \mathrm{~mm} \text { gauge } \\
\text { length minimum }\end{array}$} & \multirow[t]{2}{*}{$\begin{array}{l}\text { Hardness } \\
\mathrm{HV}_{30}\end{array}$} & \multicolumn{2}{|c|}{$\begin{array}{l}\text { Roughness }\left(R_{\mathrm{pm}}\right) \text { after } \\
\text { surface finishing }\end{array}$} \\
\hline & & & & & & Sandpaper 400 & Sandpaper 8 \\
\hline \multicolumn{8}{|l|}{ Pins } \\
\hline Aluminium AFNOR Al 6082 & 70 & 250 & 0.33 & 7 & 110 & 1.41 & 4.86 \\
\hline Brass AFNOR UZ 40 M3A & 101 & 260 & 0.35 & 10 & 150 & 0.79 & 4.56 \\
\hline Stainless steel AFNOR Z6 CND 17-12 & 196 & 200 & 0.28 & 45 & 405 & 0.45 & 2.11 \\
\hline Spring steel AFNOR $55 \mathrm{~S} 7$ & 210 & 1100 & 0.30 & 5 & 475 & 0.74 & 1.73 \\
\hline Carbon steel AFNOR XC 42 & 210 & 340 & 0.30 & 18 & 220 & 0.81 & 2.59 \\
\hline Alloyed steel AFNOR 35 NCD 6 & 210 & 930 & 0.30 & 10 & 380 & 0.53 & 1.48 \\
\hline Alloyed steel AFNOR 40 CD 4 & 210 & 700 & 0.30 & 12 & 330 & 0.83 & 2.21 \\
\hline \multicolumn{8}{|l|}{ Disc } \\
\hline Ball bearing steel AFNOR C & 210 & - & 0.30 & - & 855 & \multicolumn{2}{|c|}{0.12} \\
\hline
\end{tabular}


Table 2

Chemical composition

\begin{tabular}{|c|c|c|c|c|c|c|c|c|c|c|c|c|c|}
\hline \multirow[t]{2}{*}{ Metallic alloys } & \multicolumn{13}{|c|}{ Chemical element (wt.\%) } \\
\hline & $\mathrm{C}$ & $\mathrm{Si}$ & $\mathrm{Mn}$ & $\mathrm{Cr}$ & $\mathrm{Ni}$ & Mo & $\mathrm{Mg}$ & $\mathrm{Al}$ & $\mathrm{Cu}$ & $\mathrm{Zn}$ & $\mathrm{Pb}$ & $\mathrm{Fe}$ & $\mathrm{Ti}$ \\
\hline Al 6082 & - & $0.7-1.3$ & $0.40-1.0$ & 0.25 & - & - & $0.6-1.2$ & Bal. & 0.10 & 0.20 & - & 0.50 & 0.10 \\
\hline UZ $40 \mathrm{M} 3 \mathrm{~A}$ & - & $0.6-0.9$ & 2.4 & - & - & - & - & $1.5-2$ & $57-60$ & $32-38$ & 0.35 & 0.25 & - \\
\hline Z6 CND 17-12 & 0.05 & 1.00 & 2.00 & 17.50 & 12.00 & 2.80 & - & - & - & - & - & Bal. & - \\
\hline 55 S 7 & 0.55 & 1.70 & 0.80 & - & - & - & - & - & - & - & - & Bal. & - \\
\hline $\mathrm{XC} 42$ & 0.42 & 0.25 & 0.65 & 0.16 & 0.09 & 0.02 & - & - & - & - & - & Bal. & - \\
\hline $35 \mathrm{NCD} 6$ & 0.34 & 0.25 & 0.55 & 1.55 & 1.55 & 0.20 & - & - & - & - & - & Bal. & - \\
\hline $40 \mathrm{CD} 4$ & 0.42 & 0.25 & 0.65 & 1.05 & - & 0.20 & - & - & - & - & - & Bal. & - \\
\hline $100 \mathrm{C} 6$ & 1.00 & 0.25 & 0.30 & 1.50 & - & - & - & - & - & - & - & Bal. & - \\
\hline
\end{tabular}

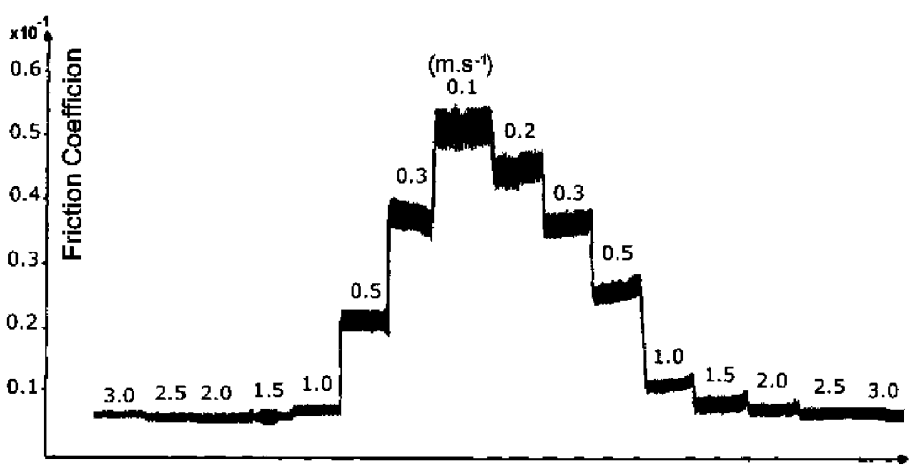

Time (min.)

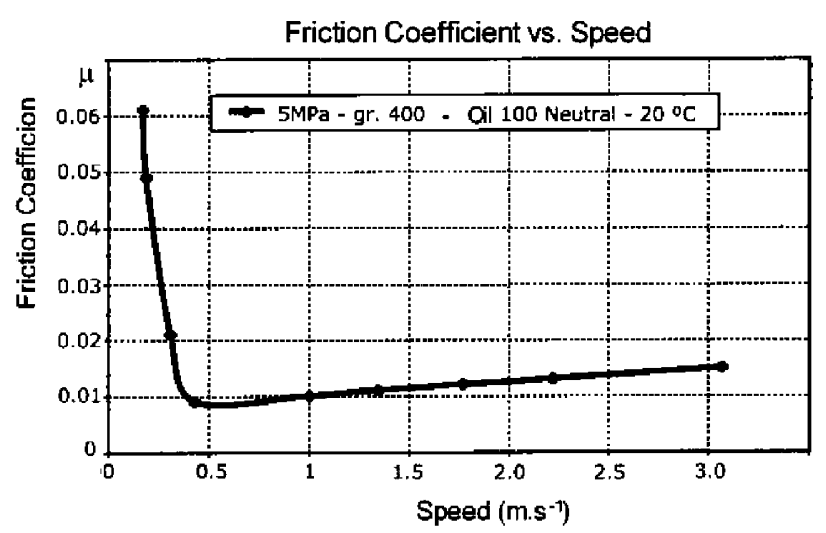

Fig. 4. The frictional diagram and the friction coefficient chart vs. speed.

$10 \mathrm{MPa}$. These were chosen to preserve as much as possible the pin surface finish at the end of each test.

The second series of tests were conducted at constant speed in order to analyse the influence of the mixed lubrication on the morphological alteration of the pin surfaces. Three lower speed values were selected from the mixed lubrication regime from the curves at a variable speed. The sliding distance was the same in every test for the same initial surface state $(7.5 \mathrm{~m}$ for the sandpaper 400 and $12 \mathrm{~m}$ for the sandpaper 80). Pressure, oil temperature, and counterface materials remain constant. The samples were observed by scanning electronic microscope (SEM), optical microscope and profilometer. The latter provides a means of obtaining roughness and surface parameters. It was also possible after testing to evaluate the degradation of the surface. Measurements with this device were carried out according to ISO 4287 standard and were also used for finding the phenomena induced by running-in.

The mass loss from the softer material was measured by weighing before and after each test. The results achieved from the variation of the mass loss are negligible since it occurred at a magnitude of $10^{-4} \mathrm{~g}$. Therefore, the quantification of the wear was not possible. Ferrography analysis was performed on the lubricants used revealing an insignificant quantity of wear debris.
The relatively low pressures used in the tests (5 and $10 \mathrm{MPa}$ ), the short test time, the fact the samples were immersed in oil and the highly finished surface of the harder material prevented significant wear.

\section{Results and discussion}

\subsection{Friction analysis}

This model applies to contact surfaces under low contact pressure. In these conditions, friction is governed by the flow of lubricant through the microchannels on the surface asperities [11].

For the pins with fine finishes, Fig. 5 represents the friction coefficient versus the sliding speed of the brass-steel pair. The friction coefficients observed at increasing speeds are always lower than the set observed at decreasing speeds. This is due to the adaptation of the surface during testing. This behaviour was confirmed in all the tests with different material pairs.

In Fig. 6, for the brass-steel pair at increasing sliding speeds, the influence of the pins' finish and the influence of the normal pressure are compared. Figs. 5 and 6 show that at low speeds the friction coefficient 


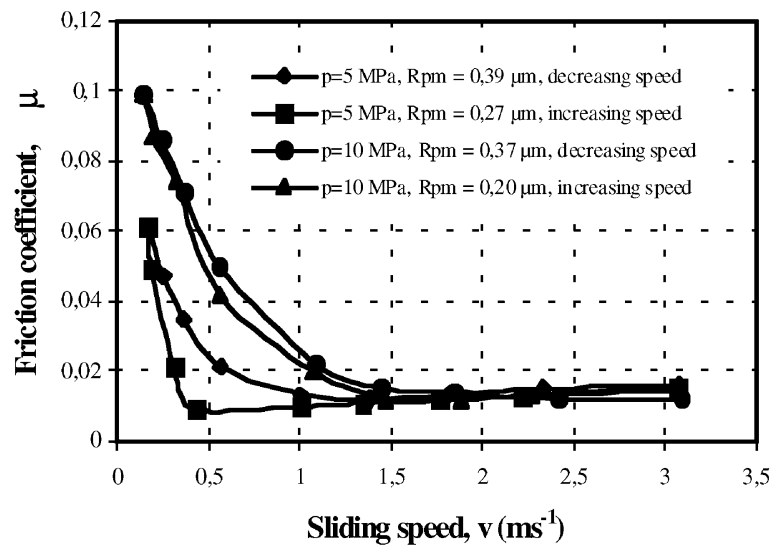

Fig. 5. Friction coefficient vs. sliding speed. Brass-steel pair, pin surface finishing by sandpaper 400 , oil $100 \mathrm{NS}$, temperature $20^{\circ} \mathrm{C}$.

is higher and gradually decreases as the sliding speed increases.

When the influence of the pressure and the lubricant viscosity are introduced in the previous diagram, the Stribeck hydrodynamic parameter is used (Eq. (2)) and the curves change, as can be observed in Fig. 7.

For finely finished pins the same figure shows that the pressure variation seems to be negligible when the hydrodynamic lubrication regime is dominant. This fact can account for the fluid pressure produced by the flow, through the microchannels, in the hydrodynamic regime. Since the lubricant is a minor source of friction, the pressure originating from the flow decreases the friction by relieving the load on roughness peaks.

The transition from mixed to hydrodynamic lubrication is more abrupt with fine finishes. With rough finishes a larger mixed lubrication area results because the effect of the solid contact on this regime is stronger [13].

In the present study, it was possible to confirm, for each pair, the importance of the introduction of the surface

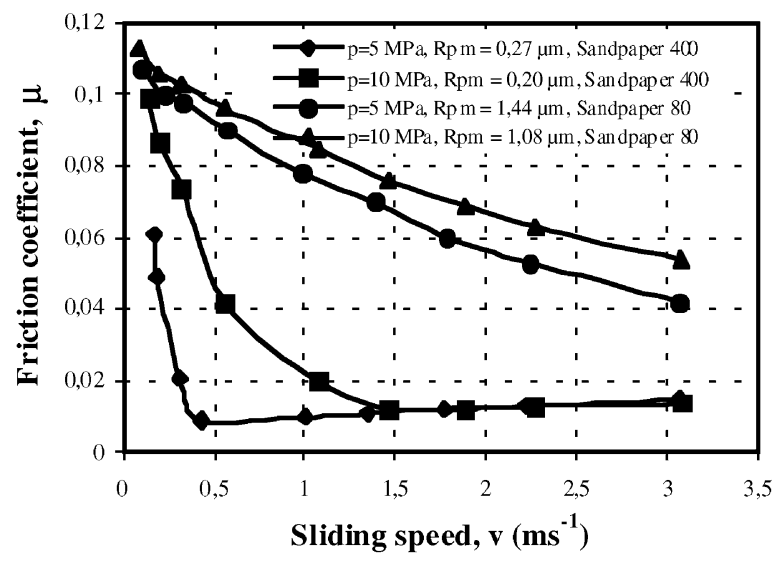

Fig. 6. Friction coefficient vs. increasing sliding speed. Brass-steel pair, pin surface finishing by sandpaper 400 and 80 , oil $100 \mathrm{NS}$, temperature $20^{\circ} \mathrm{C}$.

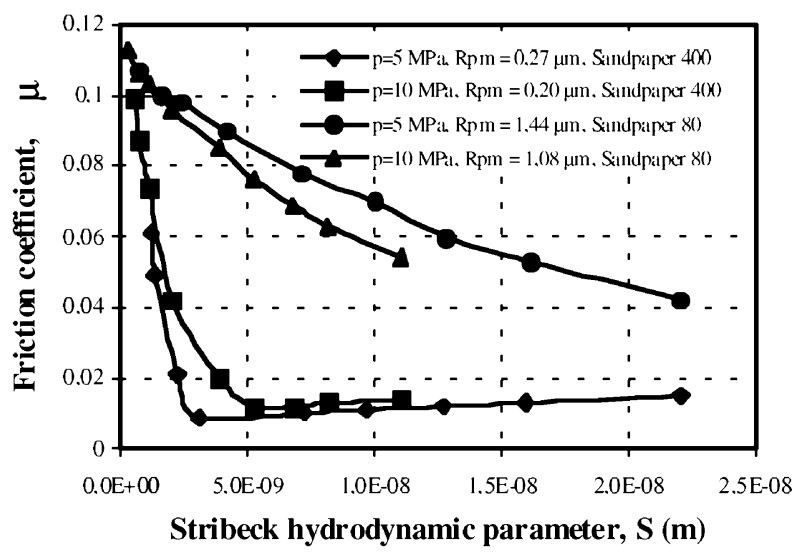

Fig. 7. Friction coefficient vs. Stribeck hydrodynamic parameter. Brass-steel pair, pin surface finishing by sandpaper 400 and 80 , oil 100 NS, temperature $20^{\circ} \mathrm{C}$. Increasing sliding speed.

roughness into the hydrodynamic parameter. The results presented here are consistent with some of the conclusions described by Emmens in his study about the influence of surface roughness on friction with lubricated systems. The roughness parameter $R_{\mathrm{pm}}$ was used when applying the hydrodynamic parameter as modified by Emmens's $S_{\mathrm{E}}$ (Eq. (3)).

In order to take into account the evolution of the microgeometry, the roughness value introduced in the Emmens's hydrodynamic parameter is the arithmetic average between the $R_{\mathrm{pm}}$ of the disc and the arithmetic average between the $R_{\mathrm{pm}}$ of the pin measured at the beginning and at the end of each part of the first test series. Table 3 shows a sample of the pin surface variation during the test.

For the previous sample (brass-steel) the hydrodynamic parameter $S_{\mathrm{E}}$, revealed the tendency for a master curve for one material pair, whatever the surface finish conditions [14], Fig. 8. The convergence of the curves for the same material pair reveals the underlying tribological phenomena what-

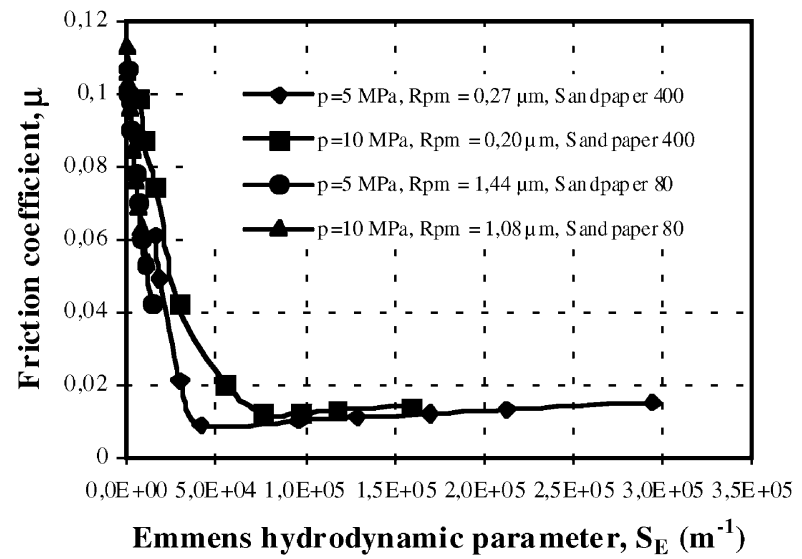

Fig. 8. Friction coefficient vs. Emmens's hydrodynamic parameter. Brass-steel pair, pin surface finishing by sandpaper 400 and 80, oil 100 NS, temperature $20^{\circ} \mathrm{C}$. Increasing sliding speed. 
Table 3

Pins roughness parameter evolution for pins surface finishing by sandpaper 400 : variable speed tests $\left(5 \mathrm{MPa}, 100 \mathrm{NS}, 20{ }^{\circ} \mathrm{C}\right.$ )

\begin{tabular}{|c|c|c|c|c|c|}
\hline \multirow[t]{2}{*}{ Metallic alloys } & \multicolumn{5}{|c|}{ Pins surface finishing by sandpaper $400, R_{\mathrm{pm}}(\mu \mathrm{m})$} \\
\hline & $\begin{array}{l}\text { Pin (at the start } \\
\text { of 1st part) }\end{array}$ & $\begin{array}{l}\text { Pin (at the end of } 1 \text { st part } \\
\text { or at the start of } 2 \text { nd part) }\end{array}$ & $\begin{array}{l}\text { Pin (at the end } \\
\text { of } 2 \text { nd part) }\end{array}$ & $\begin{array}{l}\text { Disc and pin } \\
\text { (decreasing speed) }\end{array}$ & $\begin{array}{l}\text { Disc and pin } \\
\text { (increasing speed) }\end{array}$ \\
\hline Al 6082 & 1.41 & 0.87 & 0.57 & 0.63 & 0.42 \\
\hline $\mathrm{UZ} 40 \mathrm{M} 3 \mathrm{~A}$ & 0.79 & 0.52 & 0.30 & 0.39 & 0.27 \\
\hline $55 \mathrm{~S} 7$ & 0.74 & 0.48 & 0.32 & 0.37 & 0.26 \\
\hline $\mathrm{XC} 42$ & 0.81 & 0.61 & 0.40 & 0.42 & 0.31 \\
\hline 35 NCD 6 & 0.53 & 0.43 & 0.36 & 0.30 & 0.26 \\
\hline $40 \mathrm{CD} 4$ & 0.83 & 0.63 & 0.36 & 0.43 & 0.31 \\
\hline
\end{tabular}

ever the average contact pressure and the surface roughness [15].

Figs. 7 and 8 represent the friction coefficient as a function of the hydrodynamic parameter on a linear scale. The graphs also show that, in the region where the mixed lubrication regimes are dominant, the friction coefficient is a linear function of the hydrodynamic parameter $S$ or $S_{\mathrm{E}}$.

Identical results were observed on other material pairs. The condition of $5 \mathrm{MPa}$, as a contact pressure, with fine surface finish (400-grade sandpaper) was chosen. This condition allows a larger extension of the hydrodynamic parameter on the diagram in order to compare the behaviour of the different material pairs during running-in.

Fig. 9 shows the results for the different material pairs with Emmens's hydrodynamic parameter for the above mentioned condition. The different roughness parameters result from the different material hardnesses.

A single rough surface in contact with an imaginary flat surface may represent the same contact configuration as between two rough surfaces. In order to take into account the different mechanical properties between the diverse pairs, the combined modulus of elasticity $E^{\prime}$ [9] is introduced into the Emmen's equation. The parameter used to obtain the equivalent rough surface is a combination of Young's modulus $E$ and Poisson's ratio $v$ for both materials constituting

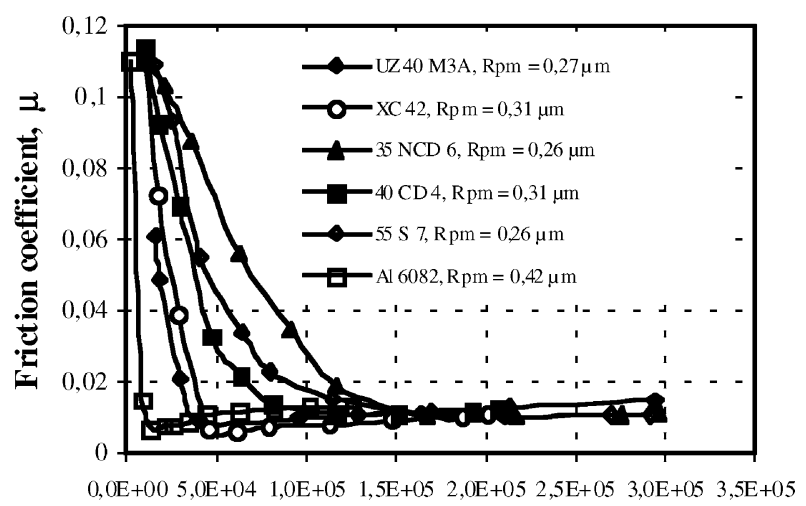

Emmens hydrodynamic parameter, $S_{E}\left(\mathbf{m}^{-1}\right)$

Fig. 9. Friction coefficient vs. Emmens's hydrodynamic parameter. Different material pairs, contact pressure $5 \mathrm{MPa}$, pin surface finishing by sandpaper 400 , oil $100 \mathrm{NS}$, temperature $20^{\circ} \mathrm{C}$. Increasing sliding speed. the sliding pair and is defined as

$\frac{1}{E^{\prime}}=\frac{1}{2}\left(\frac{1-v_{\mathrm{pin}}^{2}}{E_{\mathrm{pin}}}+\frac{1-v_{\mathrm{disc}}^{2}}{E_{\mathrm{disc}}}\right)$

The study at microscopic scale shows that surfaces are not entirely parallel: at the contact one must take into account the roughness effect and the small variations in the fluid thickness. The normal load is transmitted through solid contact (with a large friction coefficient at the summit of the highest asperities) and through intermediate fluid contact (with a low friction coefficient at the asperities situated below the height required for direct contact). In this context, it is important to take into account the geometry of the summit of the asperities and the distance between the mean line of the rough surface and the flat surface.

In this study, the deformation is considered to be elastic in both solids. Hence, according to the Hertz theory of elastic contact, the mutual approach of distant points in the two solids depends on the maximum pressure, on the radius of the contact circle and on the effective elastic modulus $E^{\prime}$ [16]. Using for $E^{\prime}$ the same exponent used in Hertz theory to take into account the elastic deformation of asperities, ( $E^{\prime}$ to the squared upon cubed) the hydrodynamic parameter equation may be written as

$S_{\mathrm{N}}=\frac{\eta V}{p} \frac{1}{R_{\mathrm{pm}}^{2}} \frac{1}{\left(E^{\prime}\right)^{2 / 3}}$

The results for the different material pairs are presented in Fig. 10, as a function of the modified hydrodynamic parameter, $S_{\mathrm{N}}$. This hydrodynamic parameter, with the contribution of the contact of stiffness of material pairs, seems to be able to reduce the gap between the curves and assure the master curve.

As can be observed in Figs. 9 and 10, for the same friction coefficient the more ductile the material (aluminium and brass) the smaller the hydrodynamic parameter.

\subsection{Surface damage}

From the friction tests at a variable speed, three speed values were chosen from the area where mixed lubrication is dominant. With these values, wear tests were carried out, 


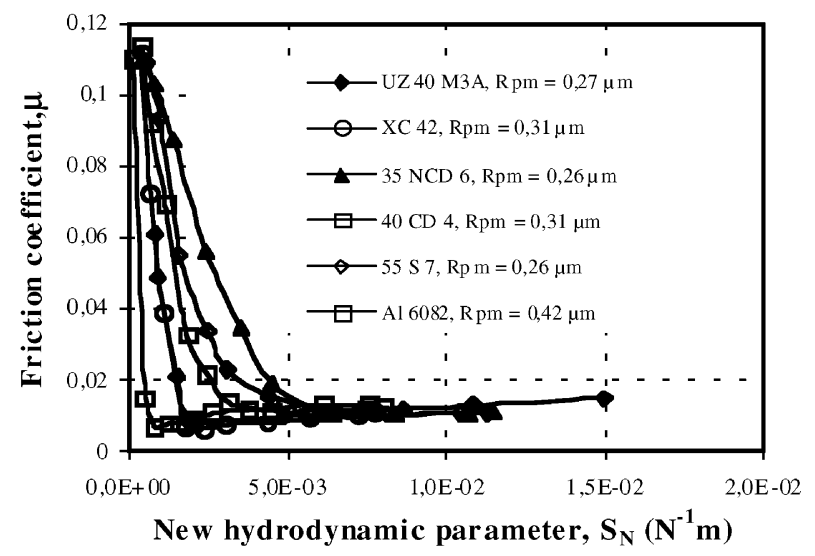

Fig. 10. Friction coefficient vs. new hydrodynamic parameter. Different material pairs, contact pressure $5 \mathrm{MPa}$, pin surface finishing by sandpaper 400 , oil $100 \mathrm{NS}$, temperature $20^{\circ} \mathrm{C}$. Increasing sliding speed.

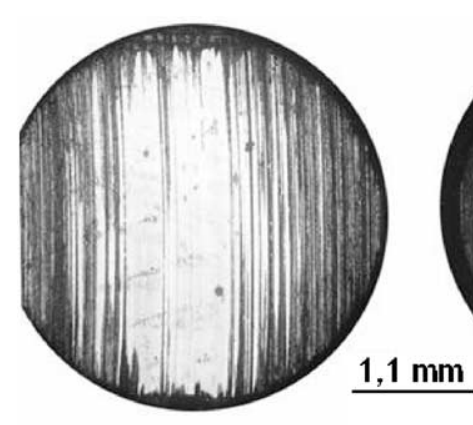

(a)

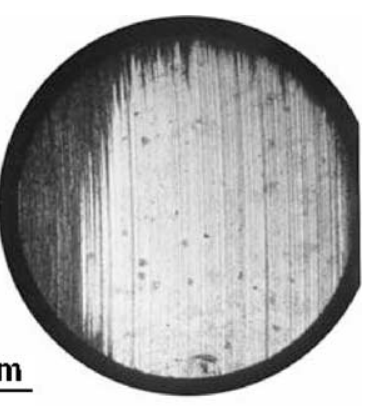

(b)
Fig. 11. Optical microscopy. Brass pins surface after constant speed tests ( $p=10 \mathrm{MPa}, T=20^{\circ} \mathrm{C}$ ). (a) Pin surface finishing by sandpaper 80 $\left(V=0.25 \mathrm{~m} \mathrm{~s}^{-1} ; t=1800 \mathrm{~s} ; \mu=0.109\right)$; (b) Pin surface finishing by sandpaper $400\left(V=0.3 \mathrm{~m} \mathrm{~s}^{-1} ; t=2400 \mathrm{~s} ; \mu=0.053\right)$.

at constant speed, to analyse the influence of these regimes on the morphological alteration of pin surfaces. The sliding distance was the same in the tests with the same surface finish. These tests confirm the friction coefficient obtained from the variable speed tests. The test conditions and the average friction coefficient for the brass-steel couple are presented in Table 4.

As sliding speeds decrease, the friction coefficient becomes higher and the normal and tangential forces acting on the pin produce ever-larger contact areas. Figs. 10 and 11

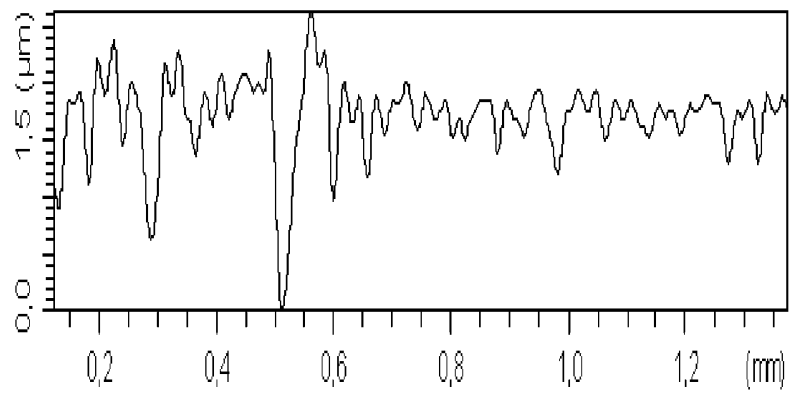

Fig. 12. Brass pin topography after testing, pin surface finishing by sandpaper 400. Normal roughness profile $\left(R_{\mathrm{a}}\right)$.

shows that at pressures of $10 \mathrm{MPa}$, the contact area is more uniform for the finer finish. At equivalent speeds, a smaller friction coefficient was observed on the surfaces having finer finishes.

The topography of the surface of each pin was plotted by profilometry. The smooth area of the pin surface, analysed in all cases, revealed the effects of the contact mechanisms. Plastic deformation was observed on the pins' surfaces. Fig. 12 shows an example of the microgeometry analysis made on the pins' surfaces after tests. The plastic deformation results in an apparent compression, because the striation crests on the finish are slightly lower in the smooth region. Similarly, for the fine-finish brass pin surface at $10 \mathrm{MPa}$, it is possible to see the finish striations on the smooth area. These observations lead to the conclusion that surfaces are not completely flat and are still undergoing running-in. Johnson [17] states that the surface smoothing during running-in is produced much more by the local plastic deformation than by the action of the wear. Moreover, during running-in the asperities acquire the optimum curvature for providing the maximum stability to the oil film [18]. When loads are excessive, the existence of a plastic flattening during the final running-in stage is inevitable. When the loads are small, only the highest asperities are plastically deformed and polished by wear. If one surface is soft and the other hard, smoothing only occurs at the softer surface if the harder surface has a very fine finish.

The topography of the surfaces also suggests that these tests were carried out under the mixed lubrication regime. With regard to the topographic alterations during running-in there are several points of view: Archard [19] suggests that a new surface would undergo plastic deformation of

Table 4

Main characteristics of constant speed tests for brass-steel pair $\left(10 \mathrm{MPa}, 100 \mathrm{NS}, 20^{\circ} \mathrm{C}\right)$

\begin{tabular}{llllrcc}
\hline Sample no. & Pin material & Pin initial roughness, $R_{\mathrm{pm}}(\mu \mathrm{m})$ & Sliding speed $\left(\mathrm{m} \mathrm{s}^{-1}\right)$ & Time $(\mathrm{s})$ & Sliding distance $(\mathrm{m})$ & Friction coefficient \\
\hline 1 & UZ 40 M3A & 4.56 & 0.25 & 1800 & 7.5 & 0.109 \\
2 & 4.56 & 0.5 & 900 & 7.5 & 0.089 \\
3 & 4.56 & 1.5 & 300 & 7.5 & 0.063 \\
4 & 0.79 & 0.3 & 2400 & 12 & 0.053 \\
5 & 0.79 & 0.8 & 900 & 12 & 0.028 \\
6 & & 1.2 & 600 & 12 & 0.013 \\
\hline
\end{tabular}




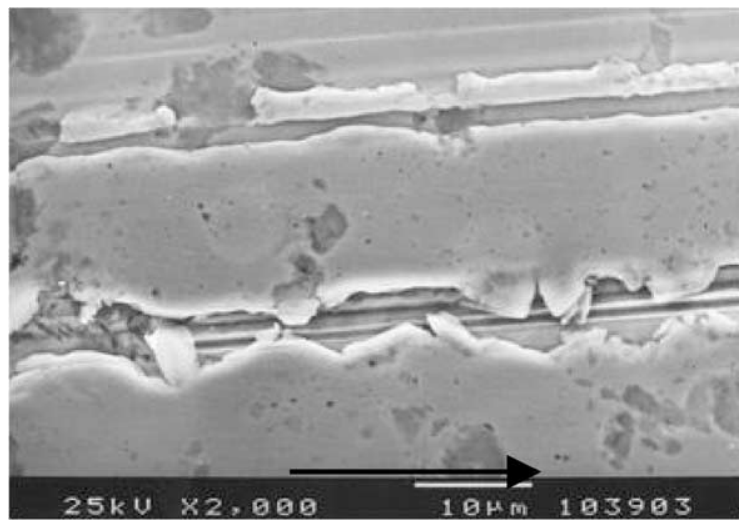

Fig. 13. Filmy wear on the brass pin surface. Pin surface finishing by sandpaper $80\left(R p_{\text {initial }}=4.56 \mu \mathrm{m}, p=10 \mathrm{MPa} ; V=1.5 \mathrm{~m} \mathrm{~s}^{-1} ; t=300 \mathrm{~s}\right.$; $\mu=0.063)$.

asperities at the outset but would run-in so that the asperities are only found at the limit of elastic deformation. Rowe and co-workers $[20,21]$ discovered that the initial topography has a dominant effect on the final roughness of the surface and on the final coefficient of friction. Kragelsky and Kombalov [22] has shown that surface roughness has a steady value during running-in and that this state corresponds to a minimum coefficient of friction the transition from the hydrodynamic to mixed lubrication.

The scanning electronic microscopy on the pin surface confirmed that a plastic deformation has occurred in the smooth area of the pin surface. In this region several discontinuities were found, which are typical of a rough surface submitted to contact processes, such as flattening of the striations and some crackling. The flat striations have the appearance of a discontinuous thin film, which results from a plastic flow at the rough surface, Fig. 13. Akagaki and Kato [23] described this behaviour as "filmy wear" formed under lubricated low friction conditions in which very thin wear particles, are extruded from the edges of the asperities on the softer surface.

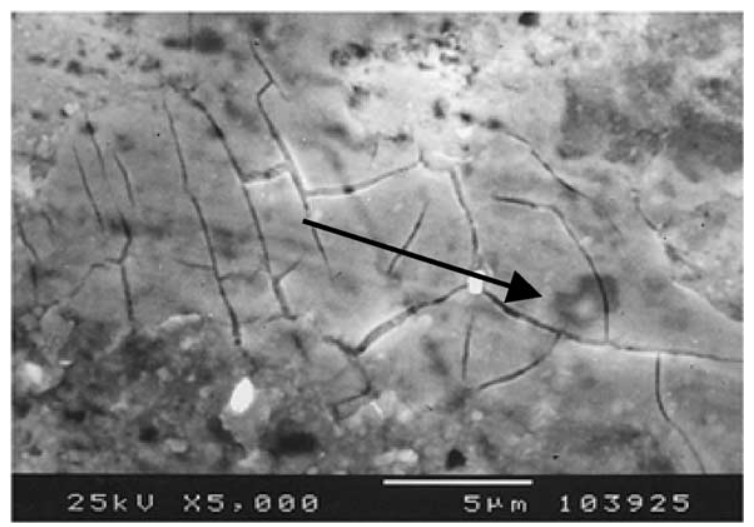

Fig. 14. Crackling on the brass pin surface. Pin surface finishing by sandpaper $400\left(R p_{\text {initial }}=0.79 \mu \mathrm{m} ; p=10 \mathrm{MPa} ; V=1.2 \mathrm{~m} \mathrm{~s}^{-1} ; t=10 \mathrm{~min}\right.$; $\mu=0.013)$.

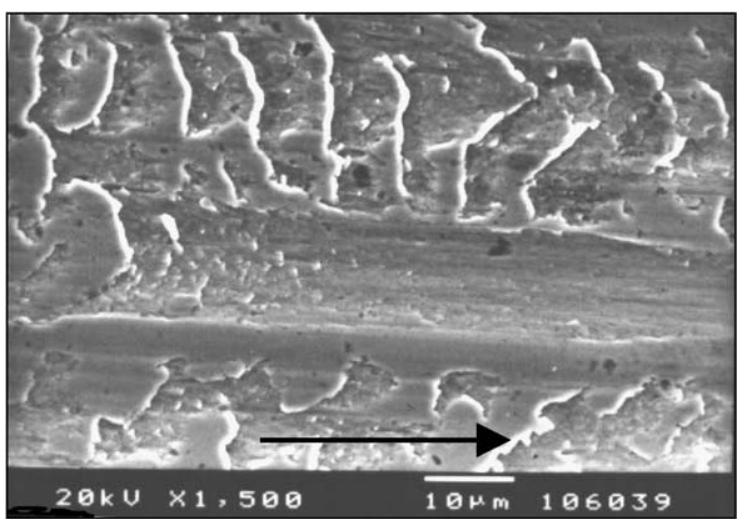

Fig. 15. Microphotography of AFNOR $55 \mathrm{~S} 7$ pin after variable speed test, contact pressure $5 \mathrm{MPa}$, pin surface finishing by sandpaper 400 .

Crack formations is more frequently found in the pins tested at lower speed where the friction coefficient is higher due to a greater solid component $\mu_{\mathrm{s}}$ (see Eq. (1)) of the mixed and boundary lubrication regime. On the smooth finish pins, crackling is much smaller and subtle. This crackling results from thermal shocks at the pin surface, leading to the production of a double-axial stress state Fig. 14.

The X-ray diffraction has not revealed any iron element from the steel discs on the surface of the brass pin.

On the variable speed tests a deformation scale type was founded on the pin surface for all materials tested, as it is possible to see in the Fig. 15 for the harder pin material, AFNOR $55 \mathrm{~S} 7$, with fine finish at $5 \mathrm{MPa}$ as a contact pressure.

\section{Conclusions}

This study presents an experimental procedure for obtaining a normalised hydrodynamic parameter as well as a means of identifying the mixed lubrication regime under running-in conditions in a lubricated environment. The following conclusions can be drawn from this research.

The influence of several factors on the friction coefficient was demonstrated and the test curves on the Stribeck diagram were drawn.

In all friction tests, various lubrication regimes were observed; but like in Emmens model no fundamental differences were found on the Stribeck diagram between boundary and mixed lubrication regimes as one might expect.

During running-in, the surface profiles changed significantly due to a smoothing of the asperities by plastic deformation. The solid contact between the asperities of the pins' and of the steel discs' surface contributed significantly to the plastic deformation. If friction is governed by the lubricant flow through microchannels, then the viscous friction component is dominant, and a decrease in the friction coefficient and a tendency for the hydrodynamic lubrication regime occurs. 
Independently of variations in the other operational variables, the surface finish influences the friction values in lubricated contacts, as was observed in the tests.

For different pairs of materials, the Emmens's hydrodynamic parameter, $S_{\mathrm{E}}$, shows a larger scatter in the friction-speed diagram.

Finally, the contribution of different material pairs by the effective elastics was introduced. In the mixed regime for an equivalent friction coefficient, the more ductile materials had a smaller hydrodynamic parameter. The option of introducing $\left(E^{\prime}\right)^{2 / 3}$ results in a smaller scatter in the data diagram. However, in future work the extensive plastic deformation over the pin surfaces should be taken into consideration when calculating the hydrodynamic parameter. Thus, the possible influence of non-elastic contact theories need to be taken into account.

As a final remark, we insist on the fact that in this experimental study the friction coefficient for the materials pairs tested is a function of only one normalised hydrodynamic parameter. This comparative work increases the possibility that in the future the hydrodynamic parameter can be used in design and conception projects, or even in production, to control the lubrication regimes and the resultant surface damage.

\section{References}

[1] G. Masouros, A. Dimarogonas, K. Lefas, A model for wear and surface roughness transients during running-in of bearings, Wear 45 (1977) 375-382.

[2] R. Östvik, H. Christensen, Changes in surface topography with running-in, in: Proceedings of the Tribology Conventions (Part 3P), Vol. 183, Institute of Mechanical Engineering, London, 1968/1969, pp. $57-65$.

[3] A.V. Sreenath, N. Raman, Mechanism of smoothing of cylinder liner surface during running-in, Int. Tribol. Int. April (1976) 55-62.

[4] P. Pawlus, A study on the functional proprieties of honed cylinders surface during running-in, Wear 176 (1994) 247-254.

[5] R. Progri, B. Paffoni, F. Robbe-Valloire, R. Gras, Introduction de l'Elastoplasticité dans la Modélisation du Régime de Lubrification Mixte, in: Proceedings of the Journées Internationales Francophones de Tribologie, Besançon, 2000.

[6] F. Robbe-Valloire, B. Paffoni, R. Progri, R. Gras, An asperity based model for friction in mixed lubrication, in: Proceedings of the Second World Tribology Congress, Vienna, 2001, pp. 77-84.

[7] P. Andersson, J. Juhanko, A.-P. Nikkilä, P. Lintula, Influence of topography on the running-in of water-lubricated silicon carbide journal bearings, Wear 201 (1996) 1-9.

[8] F. Robbe-Valloire, B. Paffoni, R. Progri, R. Gras, Modélisation du Frottement Mixte entre Surfaces Parallèles Fonctionnant en Environnement Lubrifié, in: Proceedings of Journées Internationales Francophones de Tribologie, Neuchâtel, 1997, pp. 197-203.

[9] K.L. Johnson, J.A. Greenwood, S.Y. Poon, A simple theory of contact in elastohydrodynamic lubrication, Wear 19 (1972) 91-108.

[10] F. Ghasripoor, Friction controlled materials wear testing and selection under starved lubrication, Wear 196 (1996) 207-213.
[11] W.C. Emmens, The Influence of surface rougness on friction, in: Proceedings of the Fifteenth IDDRG International Conference on Controlling Steel Metal Forming Process, Michigan, 1988, pp. 63-70.

[12] E. Felder, V. Samper, Experimental study and theoretical interpretation of frictional mechanism in steel sheet forming, Wear 178 (1993) 85-94.

[13] I. Nogueira, A. Morão Dias, R. Gras, R. Progri, Contacto de Componentes Mecânicos em Regime de Lubrificação Limite, in: Proceedings of the CEDIM'99 on Lubrificação e Tribologia, Vol. 3, Santiago do Chile, 1999.

[14] I. Nogueira, A. Morão Dias, R. Gras, R. Progri, Influência do Par de Materiais em Contacto no Parâmetro Hidrodinâmico de Lubrificação, in: Proceedings of Seventh Portuguese Journeys of Tribology, Porto, 2000, pp. 75-78.

[15] I. Nogueira, A. Morão Dias, R. Gras, R. Progri, The influence of different couples of materials in the hydrodynamic parameter, in: Proceedings of the Conference on Advances: Mechanical Behaviour, Plasticity and Damage, Vol. 1, Tours (França), Elsevier, Amsterdam, 2000, pp. 633-638.

[16] K.L. Johnson, Contact Mechanics, Cambridge University Press, Cambridge, 1985, p. 99.

[17] K.L. Johnson, Contact mechanics and the wear of metals, Wear 190 (1995) 162-170.

[18] I.V. Kragelsky, M.N. Dobychin, V.S. Kombalov, Friction \& Wear, Calculation Methods, Pergamon Press, Oxford, 1982, p. 298.

[19] J.F. Archard, Surface topography and tribology, Tribol. Int. 7 (5) (1974) 213-220.

[20] G.W. Rowe, Surface topographic changes at breakdown of thin-film lubrication, Wear 28 (1974) 125-130.

[21] G.W. Rowe, H. Kaliszer, G. Trmal, A. Cotter, Running-in of plain bearings, Wear 34 (1975) 1-14.

[22] I.V. Kragelsky, V.S. Kombalov, Calculation of value of stable roughness after running-in (elastic contact), Wear 14 (1969) 137-140.

[23] T. Akagaki, K. Kato, Plastic flow process of surface layers in flow wear under boundary lubricated conditions, Wear 117 (1987) 179196.

I. Nogueira is currently teaching at the Industrial Chemical Engineering Department, Institute Polytechnic of Tomar. She is pursuing her $\mathrm{PhD}$ at the ENSAM-École National Supérieur d'Arts et Métiers (Paris). She received her Masters in Mechanical Engineering Science at the University of Coimbra in 1993, for her studies on wear and corrosion in ceramic coats over metallic substrate.

A.M. Dias obtained his doctorat d'état in Physical Sciences in the field of the Materials Engineering at the University of Paris VI, in 1985. Today, he is a professor at the Mechanical Engineering Department, University of Coimbra and his field of research is the mechanical behaviour of materials and surfaces engineering.

R. Gras completed his doctorat d'état in physical sciences at the University of Paris VI, in 1989. He is a professor at the ISMCM-CESTI (Institut Supérieur des Matériaux et de la Construction Mécanique) Saint-Ouen, Paris and is the director of the Tribology Group at the Laboratoire d'Ingenierie des Structures Mécaniques et des Matériaux (LISMMA).

R. Progri obtained his doctorat d'état in Physical Sciences at the University of Paris VI, in 1984. He is a professor aggregate at the Institut Supérieur des Matériaux et de la Construction Mécanique (ISMCM-CESTI) at Saint-Ouen, Paris. 